\title{
Models to estimate river temperature. Example for Danube, at Oltenița in the context of climate change and anthropic impact
}

\author{
Daniela-Elena Gogoașe-Nistoran ${ }^{1,}$, Cristina Sorana Ionescu ${ }^{1}$ and Ioana Opriș ${ }^{2}$ \\ ${ }^{1}$ University Politehnica of Bucharest, Faculty of Power Engineering, Dept. of Hydraulics, Hydraulic \\ machines and Environmental engineering \\ ${ }^{2}$ University Politehnica of Bucharest, Faculty of Power Engineering, Dept. of Energy Production and \\ use
}

\begin{abstract}
Daily variation of Danube River temperature measured at Oltenitt gauging station over 9 years (2008-2016) was analysed in comparison with the air temperature measured by satellite in the same location between 1979-2020. Air temperature shows a nearly $2^{\circ} \mathrm{C}$ increase over the 40-years period, which can be attributed to both climate warming and anthropic impact. Water temperature was modeled with a sinusoidal function and variation with discharge was discussed. Long-term trend of hourly surface air temperature variation was obtained from Open Weather data. Air - water temperature dependency was fitted with a logistic function with good approximation. Resulting correlations help predict water temperature as a function of satellite - measured air temperature.
\end{abstract}

\section{Introduction}

Stream temperature is one of the most important parameters that indicates the health of the aquatic environment. River temperature is influenced both by natural (e.g., atmospheric conditions, precipitation, wind, river discharge, riparian vegetation) [1] and anthropic factors (effluent discharges temperature, high amounts of water intakes for multiple uses, such as agriculture and industry and increased urbanisation) [2, 3].

European Environment Agency assessed that the average annual temperature for the European land area for the last decade (2008-2017) was between $1.6^{\circ} \mathrm{C}$ and $1.7^{\circ} \mathrm{C}$ above the pre-industrial level, which makes it the warmest decade on record [4].

In Romania, during 1991-2019 air temperature has increased by about $1.5{ }^{\circ} \mathrm{C}$ [5]. As well, the frequency of extreme heat waves increased during the last 20 years [6,7]. These phenomena also impact river temperature, particularly during summer periods, when precipitation and discharges are the lowest.

In the context of climate change, the study of extreme heat periods is of increasing interest in general and in particular in relation with their influence on river water temperature. Identifying possible patterns of river water temperature correlations with air temperatures is of utmost concern mainly in vulnerable regions, subjected to droughts and

* Corresponding author: daniela.nistoran@upb.ro 
desertification. Romania is particularly prone to such climatic risks, due to its natural conditions such as its geographical location and relief [8], as well as to anthropogenic factors, such as deforestation and urbanization growth, that generates an increased stress on water resource availability and quality.

In Romania the area subjected to desertification, characterized by an arid, semiarid or subhumid-dry climate is about $30 \%$ of the total surface of Romania, being mostly situated in Dobrogea, Moldavia, the South of the Romanian Plain and the Western Plain. This area is mainly used in the sectors of agriculture (about $80 \%$ of the total, of which about $60 \%$ are arable land), forestry (about $8 \%$ ) and waters, especially the Romanian Plain and the Danube Delta [9]. The location of the present case study was selected to be Oltenita City, within the Romanian Plane, on Danube River.

The objective of the paper is to provide quick estimates of Danube river temperature based on its long-term variability and correlations between air and water temperatures. These can be used as a first approximation for water temperature predictions in locations prone to excessive warming.

\section{Site and data}

Oltenița is an industrial city located on the left bank of Danube river. During summers heat waves characteristic to Danube floodplain are very hot. Both water and air temperatures were available at the gauging station of Oltenita.

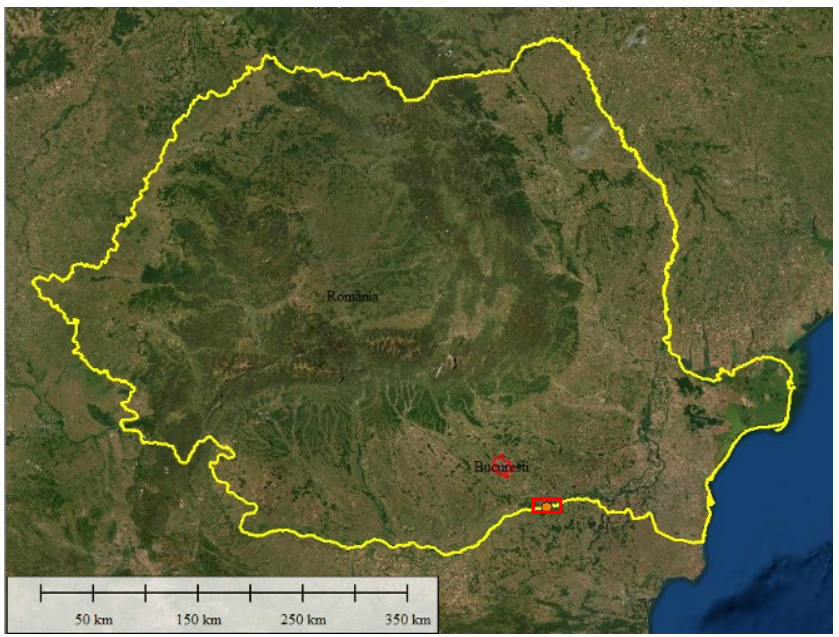

Fig. 1. Location of the example site (Oltenita gauging station, on Danube River).

Satellite hourly mean air temperature values near Oltenita gauging station $\left(44.06^{\circ} \mathrm{N}\right.$ and $26.63^{\circ} \mathrm{E}$ ), over 40 years (1979-2020), were downloaded from openweather.com (Fig. 2). OpenWeather collects and processes weather data from a vast network of over 40,000 weather stations and from meteorological broadcast services worldwide, such as satellites, radars and uses global and local weather models (set of algorithms, to improve its quality and accuracy, which is reported to be of 99\%) [10]. From the fitting line over this period, one may observe an increase of mean air temperature by nearly 2 degrees. 


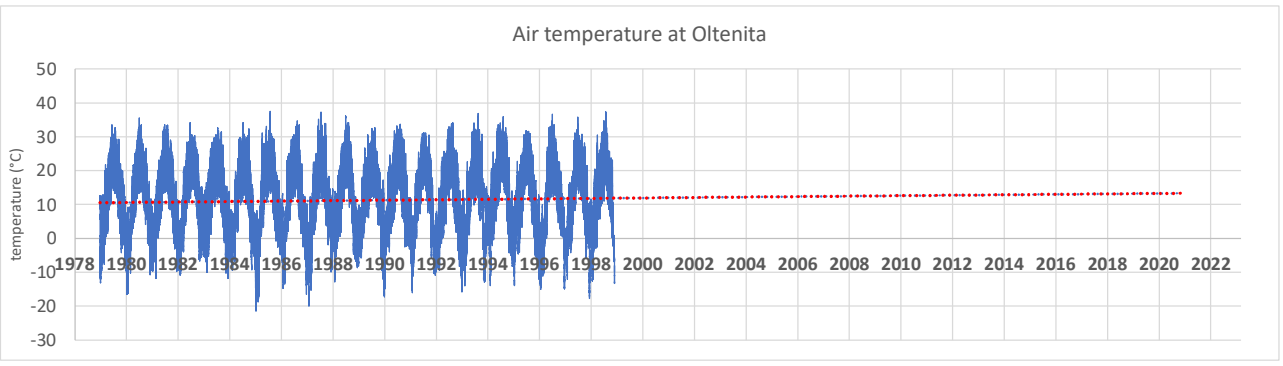

Fig. 2. Air temperature at Oltenița gauging station - satellite data at $2 \mathrm{~m}$ height from ground. Openweather.com, period 1979-2020

One may see that while until year 2000 air temperature during summer rarely overpassed $35{ }^{\circ} \mathrm{C}$, after 2000 there are several years when air temperature during summer hot waves reached $40{ }^{\circ} \mathrm{C}: 2000,2007,2012,2017$ (with a quite constant period of 5 years).

Daily mean water temperature values registered at the Olteniţa Gauging station were available from edelta.ro website for the period 2008-2015, whereas for 2016 only some random weekly data were available (Fig.3). One may observe an increase of about 1.5 degrees over this 9-years period. Also, an approximate sinusoidal annual pattern of water temperature can be seen. The maximum water temperature was registered in 2012, when the hottest summer over the period 1961-2016 was recorded [8]. Accuracy of the measured water temperature is of $0.1^{\circ} \mathrm{C}$.

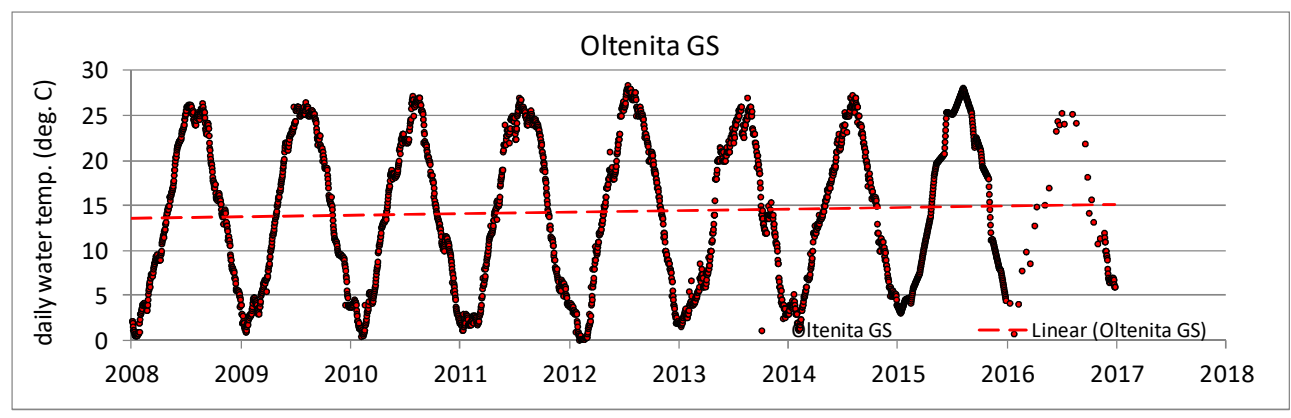

Fig. 3. Danube water temperature at Olteniţa gauging station

In order to compare air with water temperature variation during the overlapping period 2008-2016, the hourly air temperatures were averaged over each day using a HEC-DSS software, (Fig.4 and Fig. 5).

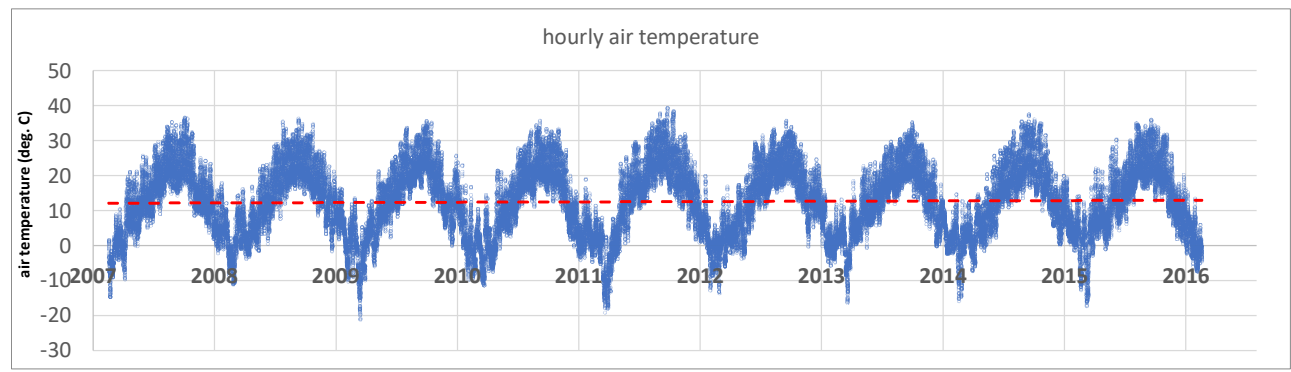

Fig. 4. Air temperature (hourly variation) at Oltenița gauging station during the study period 


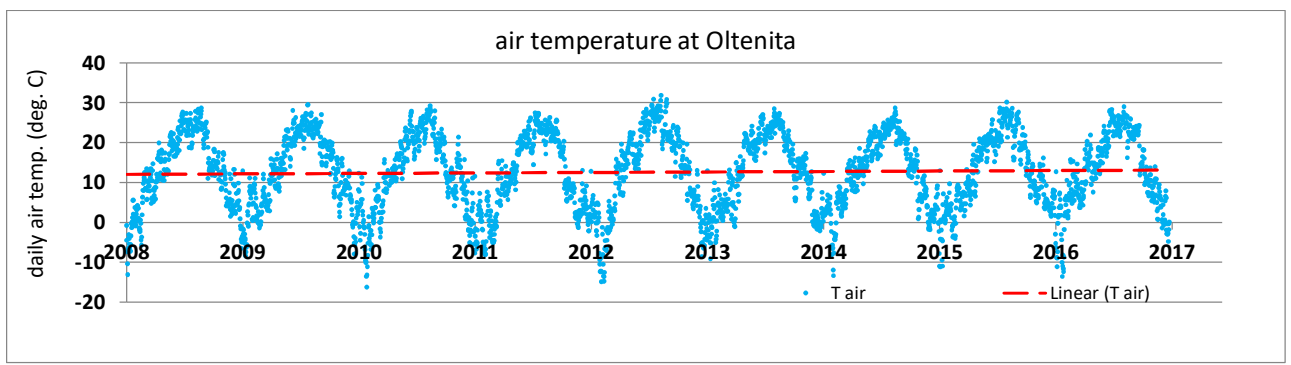

Fig. 5. Air temperature (daily average variation) at Olteniţa gauging station during the study period.

Figure 6 depicts both daily water and air temperature variations at the Oltenita gauging station. Due to its higher thermal inertia, water temperature does not fall below $0{ }^{\circ} \mathrm{C}$ during winter periods.

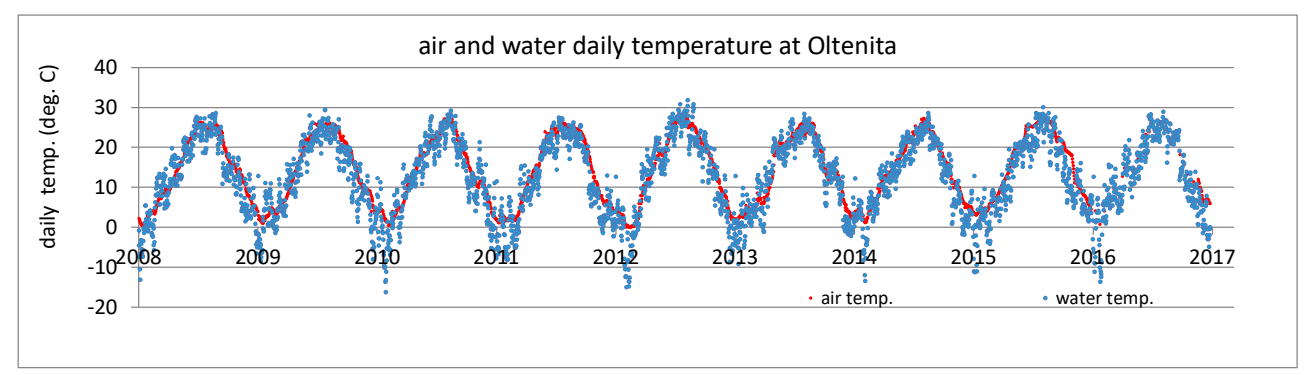

Fig. 6. Air and water temperature (daily average variation ) at Oltenița gauging station during the study period.

\section{Mathematical models}

Two models were used to reproduce water temperatures. The first model depends on time and relies on a sinusoidal variation over a year of daily water temperature [11], $T_{w}=f(t)$, given by

$$
T_{w}=T_{w 0}+A \sin \left(\pi \frac{t-t_{C}}{W}\right)
$$

where the variables for a typical year whithin the 9-year period are :

$t=$ current day (time), which may take values between 0 and 365/366 days, regardless of

the year chosen between 2008 and 2016 (the small overall increase in temperature has

been neglected for this approximation).

$A=$ the amplitude over the 9 -year period, i.e. the difference between maximum temperature

$(\alpha)$ and minimum temperature $(\mu): \mathrm{A}=28.86-0.1=28.76^{\circ} \mathrm{C}$ (considered the same for each year)

$W=$ half of the period of yearly variation $=365.25$ days $/ 2=182.625$ days

$T_{w 0}=$ mean water temperature over a year $=14.53^{\circ} \mathrm{C}$

$t_{C}=$ mean inflexion day of the year over the period, for the sinus function $=93$ of 365.25 days.

The second mathematical model uses an S-shaped logistic function that relates water with air temperatures [12], as follows :

$$
T_{w}=\mu+\frac{(\alpha-\mu)}{\left(1+e^{\gamma\left(\beta-T_{a}\right)}\right)}
$$


The parameters of the function are the following:

$\alpha=$ maximum water temperature over the study period $=28.86^{\circ} \mathrm{C}$

$\mu=$ minimum water temperature over the study period $=0.1{ }^{\circ} \mathrm{C}$

$\beta=$ air temperature of inflexion point of the S-curve

$\gamma=\mathrm{a}$ measure of the steepest slope of the function .

The model is calibrated and validated by determining the best-fitting $\beta$ and $\gamma$ parameters to the function of the paired daily data, $T_{w}$ and $T_{a}$ over the over a period of time, in this case a 9 -year time period. Even though the parameters are determined for a certain past period of study (as long as possible), the logistic function may be used to extrapolate the relationship in the future with good approximation, under similar climate conditions [2].

\section{Results}

In Fig. 7 are sholw the results of the model calibration and validation performed with the sinusoidal function with the help of Sigma Plot mathematical software. On the same graph is plotted the daily water discharge at Oltenita gauging station, over a 8-years period. Besides the air temperature, the river discharge is another important factor that controls water temperature. One may see that when the discharge is very low during summers, the water temperature increases more than the average sinusoidal function (2012 and 2015). The reverse is also valid (for examples for the years 2008, 2009 and 2011). During the calibration period there have been both wet years (such as 2010) and dry years (such as 2011) to insure proper variability of the control factors.

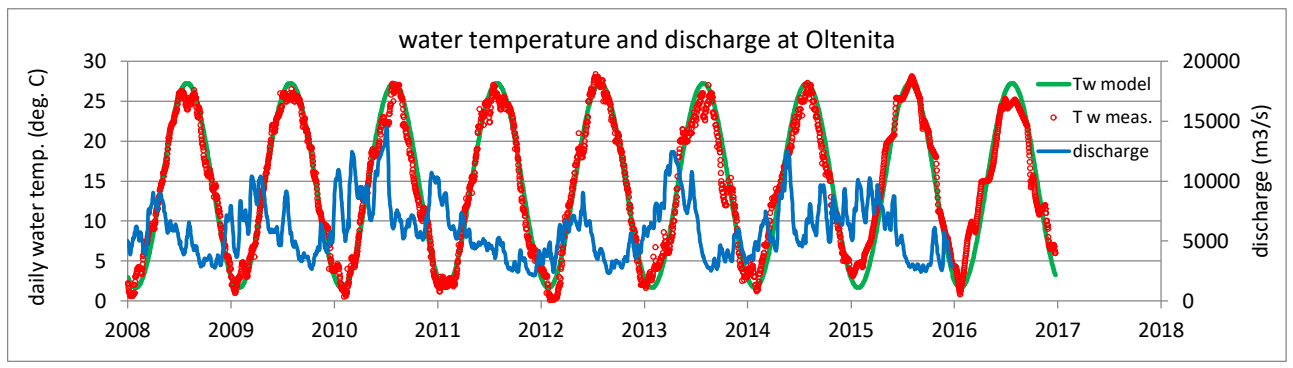

Fig.7. Air and water temperature at Oltenița gauging station over the period 2008-2017.

The absolute errors between measured and computed water temperatures defined by:

$$
\Delta T=T_{w}^{m}-T_{w}^{c}
$$

shows (Fig. 8) an overall good approximation, with values less than $4{ }^{\circ} \mathrm{C}$, besides the periods of lowest and highest temperatures from the end of winter and the end of summer (heatwaves), when these errors may even reach $6^{\circ} \mathrm{C}$. 


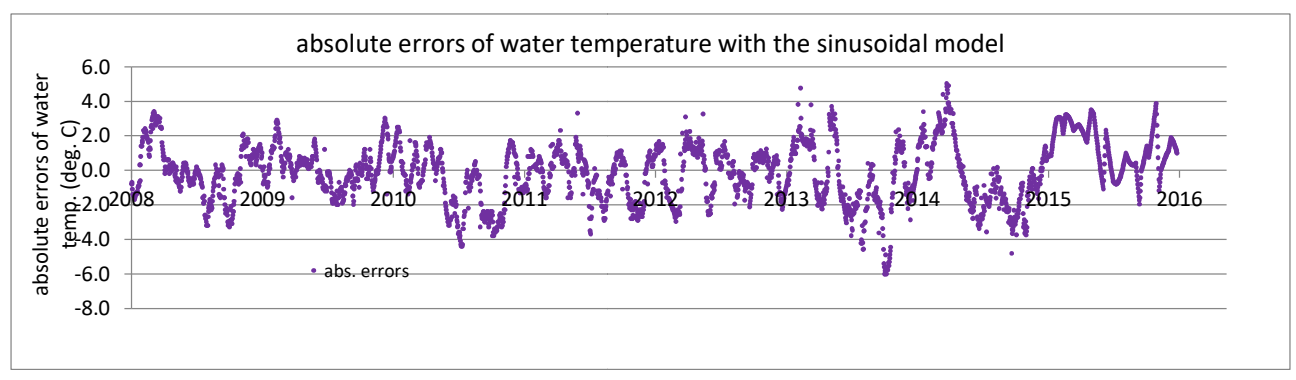

Fig. 8. Absolute errors between measured and computed water temperatures with the sinusoidal model.

Concerning the model based on a logistic function, its fitting parameters (Fig.9), were found to be: $\beta=12, \gamma=0.17416$. The adjusted R-square value for the calibration (a modified version of R-square) is 0.8353 , which proves the model is a good predictor of the data.

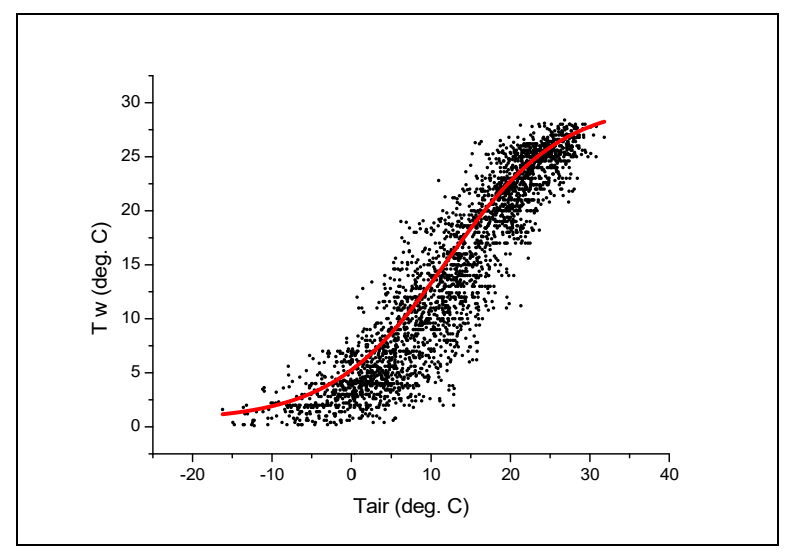

Fig. 9. Fitting of water-air temperature dependence with the logistic model.

In Fig. 10 are shown the measured and computed water temperature with the logistic model. One may see these computed values are more dispersed than the ones with the sinusoidal model, due to the sparse air temperature variation upon which depends.

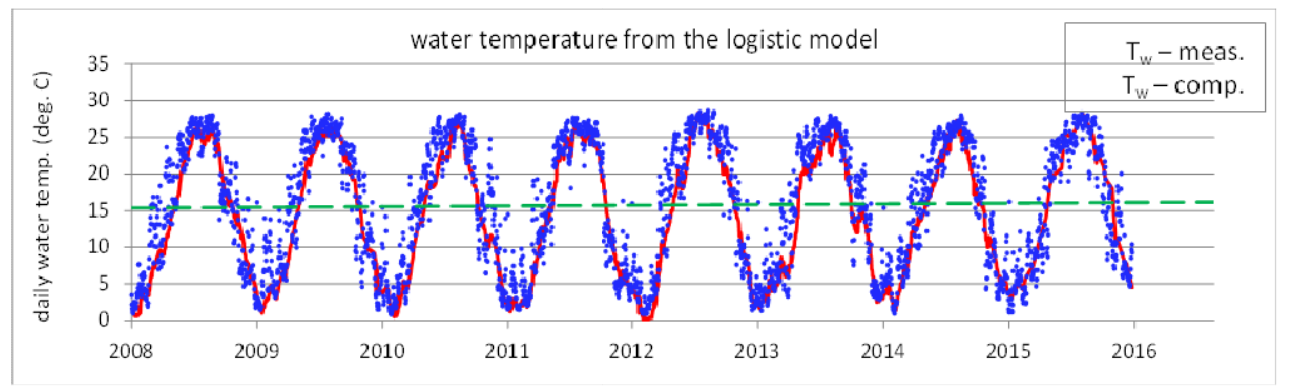

Fig. 10. Water temperature 


\section{Conclusions}

Both temperature models reproduce water temperature values with good approximation, one as a function of time, and one as a function of air temperature. One may observe the second model reproduce water temperature with a greater dispersion, due to sparse air temperature data.

The 9 years calibration and validation period included both wet and dry years, heatwave and cold spell periods. Given the good approximations between measured and computed water temperature values, under similar climatic conditions, these models could be used to forecast the river water temperature in the future over a maximum period equal to the one for which their parameters were fitted. The longer the period used to obtain the model parameters, the more accurate the prediction. However, considering the climate is changing a maximum of half of this period should be used for predicting water temperature with the same values of model parameters.

\section{References}

1. G.Garner, I.A. Malcom, J.P. Sadler, D.M. Hannah, J. Hydrol. 553, 471 (2017)

2. S.J. Dugdale, D.M. Hannah, I.A. Malcolm, Earth-Sci. Rev., 175, 97 (2017)

3. D. Caissie, Freshwater Biol. 51(8), 1389 (2006)

4. ***, Global and European temperature - Indicator assessment, Report, 2014, https://www.eea.europa.eu/data-and-maps/indicators/global-and-european-temperature$8 /$ assessment

5. ***, The climate in Romania, https://www.worlddata.info/europe/romania/climate.php

6. A. Dobrinescu, A. Busuioc, M.V. Birsan, A. Dumitrescu, and A. Orzan, Clim. Res. 64, 213 (2015)

7. A. Dumitrescu, R. Bojariu, M.-V. Birsan, L. Marin, and A. Manea, Theor. Appl. Climatol. 122, $111(2015)$

8. V. Dima, A. Irimescu, F. Georgescu, D. Mihăilescu, Heatwaves in Romania (Printech, 2016)

9. Romania's 6th National Communication on Climate Change and 1st Biennial Report (Ministry of Environment and Climate Change, 2013), https://unfccc.int/sites/default/files/6th_nccc_and_1st_br_of_romania\%5B1\%5D.pdf

10. OpenWeather, https://openweathermap.org/accuracy-and-quality, accessed May 3, 2021

11. G. Chen, X. Fang, H. Fan, J. Hydrol. Eng., 21 (10), 05016023-1 (2016)

12. S. Zeiger, J. A. Hubbart, S. H. Anderso, M. C. Stambaugh, Hydrol. Process. 30, 503 (2016) 